\title{
RISCOS OCUPACIONAISE MECANISMOS DE AUTOCUIDADO DO TRABALHADOR DE UM CENTRO DE MATERIAL E ESTERILIZAÇÃO
}

\author{
M arcia Cristina G uimarães ESPIN D O L A ${ }^{a}$, Rosane Teresinha F ONTANA ${ }^{b}$
}

\section{RESUM 0}

0 objetivo do estudo foi investigar riscos ocupacionais e mecanismos de autocuidado utilizados pelos auxiliares e técnicos de enfermagem que trabal ham em um Centro de $M$ aterial eE sterilização. E studo descritivo, de abordagem qualitativa, realizado junto a 13 trabal hadores de um hospital regional de médio porte, localizado no interior do estado do Rio Grande do Sul. Os dados foram coletados no primeiro semestre de 2010, mediante entrevistas, e analisados pelo método da análise temática. 0 risco ocupacional mais referido pelos trabalhadores foi o físico, caracterizado pelo calor. U so de equipamentos de proteção individual, hidratação e imunizações são al guns dos mecanismos utilizados pelos sujeitos para a prevenção de ag ravos e a promoção de sua saúde. A cogestão entre os sujeitos que vivenciam o trabal ho e os gestores na discussão e elaboração de ações de melhoria das condições laborais, pode construir ambiências seguras aos usuários do serviço e aos produtores de saúde.

D escritores: Saúde do trabal hador. E nfermagem do trabal ho. Riscos ocupacionais.

\section{RESUMEN}

E I objetivo del estudio fue investigar los riesgos laborales y los mecanismos de auto-cuidado utilizados por los auxiliares y técni cos de enfermería quetrabajan en un Centro de M aterial y E sterilización. E studio cual itativo, descriptivo, realizado entre 13 trabajadores de un hospital regional mediano, situado en el R io $\mathrm{G}$ rande do Sul, B rasil. L os datos fuer on recolectados en el primer semestre de 2010, a través de entrevistas y se analizaron mediante análisis temático. E I riesgo laboral más frecuente de los trabajadores es el físico, caracterizado por el calor. U so de equipo de protección personal, la hidratación y vacunas son mecanismos utilizados por los individuos para la prevención de enfermedades y promoción de su salud. E I co-manejo entre los trabajadores y la gestión en la discusión y preparación de acciones para mejorar las condiciones de trabajo pueden crear un ambiente seguro a los usuarios y a los productores de la salud.

D escriptores: Salud laboral. E nfermería del trabajo. Riesgos laborales.

T ítulo: R iesgos laborales y mecanismos para autocuidado en trabajadores de un centro de materiales y esterilización.

\section{ABST RACT}

The aim of this study was to investigate occupational risks and mechanisms of self-care used by nursing assistants and technicians working in a Sterilization and $M$ aterials $P$ rocessing $D$ epartment. This is a descriptive, qualitative approach, carried out among 13 workers of a medium-sized regional hospital, located within the state of $\mathrm{R}$ io $\mathrm{G}$ rande do Sul, B razil. D ata w ere collected on the first half of 2010 through interviews, and analyzed using thematic anal ysis. The most frequently occupational risk reported by workers was the physical risk, characterized by heat. U se of personal protective equipment, hydration and immunizations are among the mechanisms used by individuals to prevent harm and promote their health. The co- management betw een w orkers and managers in the discussion and elaboration of actions to improvew orking conditions can help building a safe environment to service users and health producers.

D escriptors: 0 ccupational health. 0 ccupational health nursing. 0 ccupational risks.

Title: 0 ccupational risks and self-care mechanisms used by the sterilization and materials processing department workers.

\footnotetext{
a M estre em E nfer magem, D ocente dos Cursos de G raduação e Pós-G raduação da U niversidade R egional Integrada do Alto U ruguai e das M issões (URI), Campus Santo Ângelo, Rio Grande do Sul, Brasil.

${ }^{b}$ Enfermeira graduada pela URI, Campus Santo Ângelo, Rio Grande do Sul, Brasil.
} 


\section{INT RODUÇÃO}

A enfermagem consiste na prestação de cuidados que incluem ações de prevenção proteção e recuper ação da saúde, tendo como foco a atenção ao usuário dos ser viços de saúde. Porém, com o advento da tecnologia aumentou a carga de trabalho e, consequentemente, a suscetibilidade dos trabaIhadores aos agravos, o que significa dizer que conjunturas advindas deste trabal ho podem causar sofrimento e adoecimento, exigindo dos pesquisadores, gestores e trabalhadores reflexões acerca da saúde do trabal hador. N este panorama, é preciso que as equipes de saúde reflitam sobre suas condições laborais levando em consideração que, antes de serem profissionais, são pessoas dotadas de necessidades que precisam ser atendidas.

A Política em Saúde do T rabalhador tem como propósito promover a melhoria da qualidade de vida e da saúde do trabal hador e, entre outras estratégias, estimular estudos e pesquisas sobre 0 tema ${ }^{(1)}$. I sto posto, conhecer situações ocupacionais para avaliar determinantes de saúde que permitam otimizar a atenção integral ao trabalhador, pode agregar valor ao humano.

É oportuno salientar que grande parte da população de trabalhadores em enfermagem é constituída por mulheres, o que pode comprometer a saúde dessas profissionais, considerando-se a sobrecarga de atividades, pois além da jornada laboral há um acréscimo de trabal ho decorrente das responsabilidades sobre as tarefas domésticas, 0 que contribui para o adoecimento e, com ele a possibilidade de afastamentos por licença para tratamento de saúde (LTS)(2), que, por sua vez sobrecarrega outro trabalhador.

Além disso, em muitas conjunturas o trabaIhador convive com a dupla jornada que, no intuito de melhorar as condições financeiras, desfavorece a vida social na medida em que dificulta o convívio com a família e amigos e o descuida do cuidado de si, o que também pode ocasionar sofrimento e adoecimento, visto que, pelas múltiplas atividades não encontra condições ou tempo para praticar atividades de lazer e esporte. N ão raramente, nas horas de folga o sujeito cuida da casa ou se dedica a outro trabal ho(3), expondo-se ao risco da sobrecarga física, psíquica, ou a outros agravos decorrentes de condições do próprio ambiente de trabalho.
Episódios de enxaqueca, estresse, irritação, desgastefísico, depressão, dores, varizes, lesões por esforços repetitivos e doenças osteomusculares relacionadas ao trabalho (LER/ D ORT), hipertensão, fadiga, acidentes ${ }^{(3,4)}$ são al guns dos ag ravos que podem ser associados a situações de risco ocupacional.

Os riscos ocupacionais comuns na atividade da enfermagem classificam-se em: químicos, representados por substâncias químicas nas formas líquida, sólida e gasosa; os físicos, gerados por radiação ionizantes e não ionizantes, vibrações, ruídos, el etricidade e temperaturas extremas; os biológicos, que compreendem os microrganismos; os ergonômicos, procedentes de mobiliário e posturas inadequadas, iluminação e ventilação deficiente; os psicossociais, decorrentes de relações conflituosas, trabal ho em turnos, monotonia ou ritmos intensos de trabal ho e os mecânicos advindos de condições do ambiente que podem conduzir ao acidente de trabal ho ${ }^{(5)}$.

Pode-se dizer que os acidentes são agravos freqüentes no exercício da enfermagem. A diversidade e a simultaneidade de car gas de trabal ho contribuem para a ocorrência dos mesmos ${ }^{(6-8)}$ e em qualquer unidade de cuidado direto ou indireto ao paciente, tais como o Centro de M aterial eE sterilização.

0 Centro de M aterial de E sterilização (CM E) é uma unidade hospitalar que presta atendimento indireto ao paciente, tendo como foco principal o processamento de materiais/ artigos utilizados no cuidado ao usuário do ser viço, em toda a sua diversidade. A credita-se que seja um ambiente com uma complexidade que favorece a exposição do trabaIhador a riscos, considerando que o sujeito trabaIha em contato com fluidos orgânicos, cal or e substâncias químicas decorrentes de processos químicos e térmicos de desinfecção e esterilização, em ambiente confinado, sob rotinas monótonas e/ ou exaustivas e não raramente insuficiente em recursos materiais e humanos.

U m estudo aponta que o trabalho repetitivo, o cansaço físico e a sobrecarga de trabal ho do CM E são alguns dos fatores que incitam nos trabalhadores desejos de serem transferidos para outra unidade e em busca de convivência com o paciente e aperfeiçoamento do cuidado de enfermagem ${ }^{(9)}$.

0 que se percebe é que estão presentes muitas causas de sofrimento nos trabal hadores destas unidades. U m estudo realizado com o objetivo de 
avaliar a morbidade referida dos trabalhadores em centro de material e esterilização verificou que $82,15 \%$ das causas de morbidade têm íntima relação com o desenvolvimento do trabal ho na unidade de CME, em decorrência, respectivamente, da manipulação excessiva de peso, de cobrança da chefia, de posturas inadequadas e, de manipulação de produtos químicos e de material contaminado ${ }^{(10)}$.

U ma pesquisa realizada em área suja dos CM Es dos hospitais de Goiânia, demonstrou um grande número de acidentes de trabalho com materiais contendo fluidos biológicos ${ }^{(11)}$, sendo prevalente o perfuro cortante, o que traz preocupação consider ando o risco de desenvolvimento de doenças infecciosas.

As seguintes questões per meiam este estudo: se o trabal hador de enfermagem tem como ocupação 0 cuidado à saúde dos indivíduos, como está 0 cuidado a sua saúde? A que riscos estão expostos os trabalhadores dos CM Es? Que mecanismos de autocuidado são usados?

Sendo assim, este estudo teve como objetivo geral investigar riscos ocupacionais e mecanismos de autocuidado utilizados pelos auxiliares e técnicos de enfermagem que trabal ham em um Centro de $M$ aterial e E sterilização.

\section{MATERIAIS E MÉTODOS}

Pesquisa de abordagem qualitativa, do tipo descritiva, realizada em um hospital de médio porte local izado no noroeste do estado do Rio G rande do Sul no primeiro semestre de 2010. Foi critério para participar da pesquisa: ser técnico ou auxiliar integ rante da equipe de enfer magem que trabal ha no centro de materiais esterilização (CM E) do hospital em estudo.

0 referido CME presta serviços a todas as unidades de cuidado e, também, a outros centros de saúde do município. É o local onde se realiza o processamento de limpeza, desinfecção e esterilização, controle, identificação, empacotamento, armazenamento e distribuição dos materiais às unidades básicas ou hospitalares.

N este hospital, trabal ham no CM E um enfermeiro e quatorze auxiliares e técnicos de enfermagem, distribuídos nos turnos manhã, tarde e noite. Todos foram convidados a participar, porém um se recusou, no que foi respeitado. Os dados foram coletados mediante entrevista, utilizando-se um formulário com perguntas abertas e um gravador.
As respostas foram transcritas na íntegra e analisadas mediante análise de conteúdo na modalidade temática ${ }^{(12)}$.

Para o tratamento dos dados, procedeu-se a exploração do material por meio da organização e leitura exaustiva das falas com vistas a entender a mensagem e seu núcleo, momento em foi feita a codificação e categorização destes dados. F inalmente, procedeu-se à interpretação, relacionando os mesmos ao referencial teórico, que forneceu condições de fundamentar e discutir os resultados da pesquisa. A análise dos dados resultou em duas categorias: Condições de trabalho: (in)satisfações e exposição a riscos e M ecanismos autopromotores de saúde.

0 estudo respeitou os preceitos éticos para a pesquisa em seres humanos e os indivíduos que aceitaram participar assinaram o Termo de Consentimento Livre e Esclarecido. Para preservar a identidade dos sujeitos, optou-se por nomeá-los por nomes de flores. 0 estudo só foi realizado mediante parecer favorável do Comitê de Ética da U niversidade Regional Integrada do Alto U ruguai e das M issões, Campus de Santo Ângelo, Rio G rande do Sul, sob protocolo n 115-4/ PPH / 09, e autorização do administrador do hospital. Vale ressaltar que, conforme normalizado pela instituição, os projetos de pesquisa devem receber ciência e autorização do administrador antes da sua realização, motivo pelo qual não se encaminhou o projeto desta pesquisa diretamente à gestão de enfermagem.

\section{RESULT ADOS E DISCUSSÃO}

\section{Caracterização dos sujeitos}

Participaram do estudo 13 sujeitos. Todos do sexo feminino, $15 \%$ são auxiliares de enfermagem e $85 \%$ são técnicos de enfer magem, com idades que variam de 23 a 55 anos de idade, sendo que $77 \%$ têm de 42 a 55 anos de idade.

Quanto ao tempo de atuação dos sujeitos que trabalham na unidade, $54 \%$ estão no serviço entre dois a três anos, sendo que $8 \%$ dos participantes trabalham há quinze anos ou mais no Centro de $M$ ateriais e Esterilização. T rabalham no horário diurno $61,5 \%$ dos sujeitos, o que pode ser justificado pelo maior número, no horário diurno, de cirurgias ou procedimentos de cuidado realizados neste hospital, característicos de instituições deste porte, nas várias especialidades. 
Tendo em vista que o município possui somente este hospital, a demanda da urgência e emergência é grande. Sendo assim o tratamento dos materiais advindos dos procedimentos destas unidades é feito nos turnos diurno e noturno, de forma ininterrupta, o que permite inferir que nem sempre o notur no é o tur no mais calmo, pois é correspondente à demanda.

\section{Condições de trabalho: (in)satisfações e exposição a riscos}

O CM E é considerado uma unidade de apoio técnico, que tem como atividades receber, separar, lavar, desinfetar e esterilizar materiais e roupas, al ém de fazer controle microbiológico e de validade do período de esterilização dos artigos processados, armazenar e distribuir esses materiais, zelando pela proteção e segurança dos oper adores ${ }^{(13)}$ e dos pacientes.

Todos os respondentes referiram que estão satisfeitos com as atividades desenvolvidas nesta unidade e referem gostar de sua ocupação, em decorrência, principalmente, das possibilidades de aprendizagem.

Sim, porque eu faço o que gosto, aprendemos coisas novas a cada dia, isso é muito importante para a minha profissão (O rquídea).

Sim, porque aprendi a trabalhar com outros instrumentos, e gostei porque só trabalhei em unidades com pessoas (H ortência).

Porém, embora todos se sintam satisfeitos com o trabal ho, os respondentes reconhecem que $0 \mathrm{am}$ biente os expõe, em especial, a riscos físicos, biológicos e químicos, classificação preval ente nas falas dos trabal hadores do CM E, seguido de al guma insatisfação relacionada às relações interpessoais, 0 que configura exposição a riscos psicossociais, os quais podem causar prejuízo à saúde física e mental destes profissionais:

R iscos materiais biológicos e químicos, calor, acidente de trabalho, cansaço, dores, pressão de colegas ( $M$ argarida).

E xposição a materiais biológi cos, calor, descaso de colegas de outros setores diz endo que aqui é um lugar de velhos, funcionários problemas e de lavadei ras, pressão de chefias atribuindo muitas ocasiões função que não são do nosso cargo (Rosa).
P ressão de chefia. Q uando fui transferida para cá qualquer coisa era motivo para assinar advertência, mas melhorou muito agora (M argarida).

É válido ressal tar que 12, dos 13 respondentes referiram o calor como 0 agente que mais os expõe no trabalho. Sendo assim, a exposição aos riscos físicos, representada pelas al tas temper aturas e pel a ventilação deficiente foi preval ente nas respostas. É válido referir que pela classificação da Organização Pan-A mericana de Saúde (OPA S)(5), a ventilação deficiente caracteriza-se como risco ergonômico, que, neste estudo, está intimamente ligada ao calor, um risco físico.

U m estudo que buscou avaliar a temperatura e a umidade do meio ambiente dos CM Es de seis hospitais em L ondrina, Paraná(14), demonstrou que a temper atura ambiental das unidades pesquisadas estava acima do preconizado pela N orma Regulamentadora $n=17^{(15)}$, que é de 20 a 23ㄷ. E mbora uma das unidades estivesse com a temperatura mais baixa, al cançada por um climatizador, esta condição não oferecia conforto térmico(14). Semelhante ao nosso estudo o calor foi um dos desconfortos mais relatados pelos sujeitos. Vale salientar que a legislação brasileira acerca dos limites adequados de temperatura ambiental para conforto térmico divergem entre si, mas pode-se dizer que estão entre 18 e $25^{\circ} \mathrm{C}^{(15,16)}$.

Confor me as normas recomendadas pelo $\mathrm{M} \mathrm{i-}$ nistério da Saúde, as janelas do CM E devem ser altas e fechadas quando a ventilação é feita por ar condicionado, ou altas e abertas, providas de telas de nylon, para evitar a entrada de vetores, na ausência de um sistema de climatização. A temperatura adequada no ambiente de trabal ho, segundo estas recomendações deve ser entre $18^{\circ}$ e $25 \circ C$, sendo que esta mesma temperatura deve ser mantida, principal mente onde se local izam as autoclaves ${ }^{(16)}$.

A maioria dos sujeitos avalia como regular suas condições de trabalho.

R egular, é muito quente no verão, não tem água boa e a área física não éadequada para o CM E (F lor-de-lis).

R egular. M otivo: muito quente o local de trabalho; local muito baixo (Crisântemo).

Os respondentes consider am a ár ea física inadequada e o ambiente, além de quente, é considerado pelos sujeitos como desconfortável ao desenvolvimento do trabalho. 
A falta de estrutura física, equipamentos, por exemplo: máquinas, estufas (Orquídea).

Seria bom se tivéssemos um lugar maior e mais ade quado para realizar tarefas, mas já tem promessas de um novo CM E (Rosa).

$\mathrm{N}$ ão foi intenção do estudo avaliar as dimensões da área física do CM E de acordo com a legislação sanitária, porém é visível que o teto é baixo e a ventilação inadequada, com precária renovação de ar.

A área para recepção, descontaminação e separ ação de materiais e roupas e a área para a lavagem, deve ter $0,08 \mathrm{~m}^{2}$ por leito (cálculo feito a partir do número de leitos do hospital) com área mínima de $8,0 \mathrm{~m}^{2}$ e a área para preparo de materiais e a área para esterilização física e química líquida de $0,25 \mathrm{~m}^{2}$ por leito com área mínima de $12,0 \mathrm{~m}^{2}$, dependendo do equipamento utilizado, sendo que a distância mínima entre as autoclaves deve ser de $20 \mathrm{~cm}$. A sala de armazenagem e distribuição de materiais e roupas esterilizados deve representar $0,2 \mathrm{~m}^{2}$ por leito com o mínimo de $10,0 \mathrm{~m}^{2}$ e contar com ar condicionado e a área para armazenamento e distribuição de materiais esterilizados e descartáveis deve compreender $25 \%$ da área de ar mazenagem de material esterilizado(13).

Estudos demonstram que, assim como na realidade estudada, o dimensionamento da estrutura física e a ventilação do CME de alguns hospitais ainda são negligenciadas ${ }^{(17-19)}$. A s al tas temperaturas podem provocar desconforto, queda na produtividade, ajuizando negativamente na qual idade do reprocessamento de $\operatorname{artigos}^{(19)}$, em especial se for considerado que a região na qual está local izado 0 hospital tem registrado temperaturas que variam de 35 a 40ํㅡ, em média, no verão.

A disposição física do CM E tem importância significativa no controle das infecções hospitalares, uma vez que podem interferir nas etapas do processamento dos artigos e suas necessárias barreiras microbiológicas, que, se inadequadas, favorecem a transmissão de microrganismos.

E $m$ relação a sua contribuição para mel horias nas condições de trabalho, alguns sujeitos citam que a mudança deverá iniciar por parte dos gestores, no entanto se houver diálogo com a equipe podem ocorrer prog ressos, pois o diál ogo com os atores de um processo de trabal ho só tem a contribuir para a construção de ambiências saudáveis, e os sujeitos estão dispostos a cooperar para que isso aconteça.

J á contribuo; coloco as necessidades mais urgentes para ser resolvida com a chefia (G loxínia).

O uvindo etrocando opiniões com toda a equipedetrabalho (F lor-de-lis).

Algumas medidas podem minimizar o calor nesta unidade, tais como conservar isoladas as câmaras de vapor das autoclaves, a fim de evitar que o cal or se dissipe para todo o ambiente. "O local de isolamento das câmaras de vapor deve conter exaustores que façam esse ar quente ser circulado para fora desse local". A lém disso, é recomendado "instalar e manter adequadamente o funcionamento de ar condicionado nos vários setores do CM E "(14).

Sendo assim, pode-se inferir que, uma reavaliação da área física do local cujo ofício principal é o emprego da energia térmica, poderia aumentar o confor to e a satisfação de quem trabal ha na unidade, promovendo saúde e prevenindo agravos. É preciso "olhar" para o CM E, pois nesta instituição ainda são tímidos os investimentos nas condições ambientais de trabal ho. I nformal mente, foi informado aos pesquisadores que o climatizador não funciona adequadamente e várias tentativas de melhorias já foram encaminhadas à direção da instituição, sem respostas.

\section{M ecanismos autopromotores de saúde}

A o serem questionados sobre o que realizavam em sua rotina individual para promover a saúde e prevenir agravos, um participante respondeu:

F aço caminhadas três vezes na semana (F lor-de-lis).

Os outros sujeitos afirmaram utilizar Equipamentos de Proteção Individual (EPI's), hidratar-se para evitar desidratação já que o ambiente é muito quente e, imunizar-se contra al gumas doenças, tais como hepatite e gripe.

E mbora escape do intuito da pesquisa, emerge um resultado que induz à seguinte reflexão: a maioria dos técnicos e auxiliares ao responderem esta pergunta, associou o autocuidado à rotina de trabalho, desvinculando ações de promoção e prevenção à vida pessoal e individual, externa à sua atividade laboral, o que serve de alerta para que 
se pense em ações de educação em saúde também fora do trabal ho. Por outro lado é um dado animador, considerando que a grande maioria referiu uso de EPI's e cuidados para evitar acidentes, o que, novamente, consolida a importância que o trabaIhador atribui ao uso de E PI para prevenção de acidentes de trabalho, tais como demonstrado nas falas:

U so deE PI, adequadamente, mais uniformes, vacinações em dia e exames laboratoriais mais seguidos (G érbera).

Faço tudo com prevenção, uso luvas, máscaras e lavo bastante as mãos (H or tência).

F aço exames periódicos, vacinas em dia, uso E PI adequado (G loxínia).

Tomando cuidado com manuseio das autoclaves, estufas, tomando muito líquido para não desidratar (Violeta).

Os trabal hadores referiram que a instituição disponibiliza equipamentos de proteção individual, porém encontram alguma dificuldade de adaptação a estes equipamentos. Pouco mais da metade dos respondentes referiu ter dificuldades no uso de alguns tipos de EPI's.

Sim, luva de borracha é de difícil manuseio perde a sensibilidadee avental quedeveser individual eécole tivo (M argarida).

Sim, porque muitas vezes dificultam o manuseio dos materiais (Rosa).

M esmo referindo adesão ao uso de EPI's, a maioria $(46,15 \%)$ já sofreu algum dano/ acidente relacionado ao desempenho de suas atividades, decorrentes da exposição à substâncias químicas, a fluidos biológicos e ao calor, tais como queimaduras, acidente com glutaraldeído, epor picada deaguIha, sendo este último o prevalente nas falas. Destes, apenas um trabal hador revelou não ter notificado 0 acidente. Para evitá-lo, os respondentes foram unânimes em responder que utilizam mecanismos de prevenção aos ag ravos no trabal ho como tomar cuidado no manuseio com o material, com as máquinas e, usar EPI.

Sim, glutaral deido no olho (A zaléia).
Sim queimaduras, não fiz comunicação [ Comunicação de A cidentes de T rabalho (CAT )] (Begônia).

Sim, me piquei com agulha, fiz CAT, mais exames tomei kit H IV (G érbera).

Os acidentes de trabalho estão causando sofrimento e ag ravos nos trabal hadores da enfermagem em decorrência da fatigante exposição a cargas diver sas e simultâneas, à escassez de recursos e, até mesmo, à desatenção e negligência do próprio trabalhador ${ }^{(6-8)}$ sendo que os acidentes com material perfuro cortante e os que envolvem mucosas são de magnitude significativa, especialmente os advindos do contato com microrganismos oriundos do contato com o paciente e/ ou com artigos contaminados ${ }^{(20)}$.

Como se pode apreender, em diferentes dimensões e de acordo com a complexidade da unidade, do ritmo e das cargas envolvidas no processo de trabal ho, a exposição a riscos ocupacionais é situação preocupante e merece a atenção de pesquisadores e dos gestores, a fim de que seja possível trabal har de forma segura. I nvestir em educação permanente em saúde, nas comissões de prevenção de acidentes e na cogestão dos processos de trabalho, podem ser estratégias de promoção da saúde individual e coletiva, que agregada à gestão participativa e atenta às necessidades do trabal hador favorece a construção de ambiências saudáveis ao usuário e ao trabalhador.

\section{CONSIDERAÇÕES FINAIS}

M ediante os resultados encontrados nesse estudo percebeu-se que os sujeitos estão, de um modo geral, satisfeitos com seu trabal ho e cientes de que a atividade nesta unidade requer 0 uso adequado de EPI's para protegê-los dos riscos biológicos, mecânicos, ergonômicos, entre outros.

U ma grande preocupação dos participantes refere-se à estrutura física da unidade, devido ao prejuízo a sua saúde como as al tas temper aturas e baixa al tura do teto, o que lhes causa desconforto. E mbora os aspectos arquitetônicos ou de dimensões físicas não fossem o principal interesse deste estudo, tornou-se evidente a inquietação dos sujeitos acerca da área física. E studos que avaliem a organização físico/arquitetônica com vistas à segurança e saúde do trabal hador desta unidade são indicados. 
Quanto à exposição a riscos ocupacionais, 0 calor foi um agente citado como muito desconfortável. A implementação de melhorias para fomentar a qualidade de vida no trabal ho deve ser uma prioridade da gestão/ dos gestores, tais como investimentos em climatização e em reestruturação da área física, de modo a favorecer o conforto. T rabalhadores satisfeitos tendem a realizar suas atividades com mais atenção, acolhimento e cordialidade, o que contribui para a humanização nas relações. Não se pode negligenciar que a qualidade do trabalho, da segurança ao usuário é, também, advinda dos materiais corretamente processados no CME.

Acredita-se que estudar o trabal ho do ponto de vista do trabalhador, diminui equívocos de avaliação. N ão basta a racionalidade dos pesquisadores e técnicos, é preciso envolver aquele que vive a situação de trabal ho para que, a partir das singularidades, efetivamente, haja construção coletiva. F inalmente, é válido ressaltar que, para o objetivo proposto a este estudo, não foram encontradas limitações significativas à sua execução.

\section{REFERÊNCIAS}

1 M inistério da Saúde (BR ). Portaria n 1.125, de 6 de julho de 2005: dispõe sobre os propósitos da política de saúde do trabal hador para o SU S [ I nter net] . Brasília (D F ); 2005 [ citado 2010 abr 20] . D isponível em: http:/ / dtr2001.saude.gov.br/sas/ PORTARIAS/ Port2005/ G M / G M -1125.htm.

2 G ehring Junior G, Corrêa F ilho HR, Vieira N eto JD, Ferreira NA, Vieira SVR. A bsenteísmo: doença entre profissionais de enfermagem da rede básica do SU S Campinas. Rev Bras E pidemiol. 2007;10(3):401-9.

3 Elias M A, N avarro VL. A relação entre o trabalho, a saúde e as condições de vida: negatividade e positividade no trabal ho das profissionais de enfer magem de um hospital escola. Rev Latino-Am Enfermagem. 2006;14(4):517-25.

4 L eitão I M TA A, Fernandes A L, Costa Ramos IC. Saúde ocupacional: anal isando os riscos relacionados à equipe de enfermagem numa unidade de terapia intensiva. Ciênc Cuid Saúde. 2008;7(4):476-84.

5 M inistério da Saúde (BR); Organização Pan-A mericana da Saúde. D oenças relacionadas ao trabal ho: manual de procedimentos para os serviços de saúde [ I nternet]. Brasília (DF); 2001 [ citado 2010 out 04] .
Disponível em: http:/ / www.opas.org.br/ sistema/ arquivos/ Saudedotrabal hador.pdf.

6 Ribeiro EJG, Shimisu HE. A cidentes de trabal ho com trabal hadores de enfer magem. Rev Bras E nferm. 2007; 60(5):535-40.

7 Secco IAO, Robazzi M LCC, Shimizu DS, Rubio M M S. A cidentes de trabal ho típicos envolvendo trabal hadores de hospital universitário da região sul do Brasil: epidemiologia e prevenção. Rev Latino-A m E nfermagem. 2008;16(5):824-31.

$8 \mathrm{G}$ allas SR, Fontana RT. Biossegurança e a enfermagem nos cuidados clínicos: contribuições para a saúde do trabal hador. Rev Bras Enferm. 2010;63(5):78692.

9 L opes D F M , Silva A, G uaranhani M L, M erighi M AB. Ser trabal hador de enfer magem da U nidade de Centro de $M$ aterial: uma abordagem fenomenológica. Rev Esc Enferm USP. 2007;41(4):675-82.

10 Leite PC, Silva A. M orbidade referida em trabalhadores de enfermagem de um Centro de $M$ aterial e E sterilização. Ciênc Cuid Saúde. 2007;6(1):95-102.

11 T ipple AFV, Sousa ACS, Almeida AN G, Sousa SB, Siqueira KM . A cidente com material biológico entre trabal hadores da área de expurgo em centros de material e esterilização. Acta Sci Health Sci. 2004;26 (2):271-8.

12 M inayo M CS. 0 desafio do conhecimento: pesquisa qual itativa em saúde. 8ª ed. São Paulo: H ucitec; 2008.

13 M inistério da Saúde (BR), A gência N acional de Vigilância Sanitária. Resolução de D iretoria Colegiada no 50, de 21 de fevereiro de 2002: regulamento técnico para planejamento, prog ramação, elaboração e avaliação de projetos físicos de estabel ecimentos assistenciais de saúde. Brasília (DF); 2002.

14 Ribeiro RP, Camargo E M OA, Viana LAC. Avaliação da temperatura nos centros de materiais esterilizados. Cogitare Enferm. 2008;13(2):268-74.

15 M inistério do T rabal ho eE mprego (BR). N orma Regulamentadora no 17 [ I nternet]. Brasília (DF); 1990 [ citado 2010 dez 20]. D isponível em: http:/ / www. mte.gov.br/ legislacao/ normas_regulamentadoras/ nr_17.pdf.

16 M inistério da Saúde (BR), Secretaria de A ssistência à Saúde, Coordenação-G eral das U nidades H ospita- 
lares P róprias do Rio de Janeiro. O rientações gerais para Central de Esterilização [ Internet] . Brasília (DF); 2001 [ citado 2010 dez 17]. Disponível em: http:// bvsms.saude.gov.br/ bvs/ publicacoes/ orientacoes_gerais_central_esterilizacao_pl.pdf.

17 Leite F B. Central de material esterilizado: projeto de reestruturação e ampliação do hospital regional de F rancisco Sá [ I nter net]. Brasília (DF): M inistério da Saúde; 2008 [ citado 2010 dez 02] . D isponível em: http:/ / bvsms.saude.gov.br/ bvs/artigos/ artigo_CME_flavia_leite.pdf.

18 Guadagnin SVT, Primo M GB, Tipple AFV, Souza ACS. Centro de material e esterilização: padrões arquitetônicos e o processamento de artigos. Rev
Eletrônica Enferm [ Internet] . 2005 [ citado 2010 nov 29];7(3):285-93. Disponível em: http:/ / www. revistas.ufg.br/index.php/ fen/ article/ view/ 905/ 1104.

19 G uadagnin SVT, T ipple A FV, Souza ACS. Avaliação arquitetônica dos centros de material e esterilização de hospitais do interior do estado de G oiás. Rev E letrônica E nferm [ I nternet] . 2007 [ citado 2010 nov 29];9(3):656-73. D isponível em: http:/ / www.fen.ufg. br/ revista/ v9/ n3/ v9n3a07.htm.

20 Dalarosa M G, L autert L. A cidente com mate-rial biológico no trabalhador de enfermagem em um hospital de ensino: estudo caso-controle. Rev Gaúcha Enferm. 2009;30(1):19-26.
E ndereço da autora / Dirección del autor / Author's address:

Rosane T er esinha Fontana

Rua Sete de Setembro, 1126

98800-000, Santo Ângelo, RS

E-mail: rfontana@urisan.tche.br
Recebido em: 16/ 02/ 2011

A provado em: 02/ 03/ 2012 